\title{
THE EFFECT OF COST SHARING ON THE USE OF ANTIBIOTICS IN AMBULATORY CARE: RESULTS FROM A POPULATION-BASED RANDOMIZED CONTROLLED TRIAL
}

\author{
Betsy Foxman, ${ }^{1,2}$ R. Burciaga Valdez, ${ }^{1,4 *}$ Kathleen N. Lohr, ${ }^{1}$ \\ George A. Goldberg, ${ }^{1,3}$ Joseph P. Newhouse ${ }^{1}$ and Robert H. Brook ${ }^{1,4,5}$ \\ 'Health Sciences Program, The Rand Corporation, Santa Monica, California and Washington DC, \\ U.S.A. ${ }^{2}$ The Department of Epidemiology, University of Michigan, Ann Arbor, U.S.A., ${ }^{3}$ Health \\ Data Institute, Inc., Lexington, Massachusetts, U.S.A., ${ }^{4}$ Department of Public Health, University \\ of California, Los Angeles, U.S.A. and ${ }^{5}$ Department of Medicine, University of California, Los \\ Angeles, U.S.A.
}

(Received in revised form 5 August 1986)

\begin{abstract}
Little is known about how generosity of insurance and population characteristics affect quantity or appropriateness of antibiotic use. Using insurance claims for antibiotics from 5765 non-eiderly people who lived in six sites in the United States and were randomly assigned to insurance plans varying by level of cost-sharing, we describe how antibiotic use varies by insurance plan, diagnosis and health status, geographic area, and demographic characteristics. People with free medical care used $85 \%$ more antibiotics than those required to pay some portion of their medical bills (controlling for all other variables). Antibiotic use was significantly more common among women, the very young, patients with poorer health, and persons with higher income. Use of antibiotics for viral, viral--bacterial, and bacterial conditions did not differ between free and cost-sharing insurance plans, given antibiotics were the treatment of choice. Cost sharing reduced inappropriate and appropriate antibiotic use to a similar degree.
\end{abstract}

Antibiotics Drugs Health Insurance Experiment Cost sharing Utilization Controlled trial Ambulatory care Prescribing practice

\section{INTRODUCTION}

THE VOLUME of antibiotics used in this country is enormous, 105 million prescriptions in 1980 [1], but surprisingly little is known about their use in the general population. Even descriptive data relating antibiotic use to demographics tends to be limited to those gleaned from special groups such as Medicaid recipients [2,3].

*Requests for reprints should be sent to Dr R. Valdez, The Rand Corporation, 1700 Main Street, Santa Monica, CA 90406-9972, U.S.A.

The views expressed are those of the authors and do not necessarily represent those of the Department of Health and Human Services or The Rand Corporation.

Supported by a Health Insurance Study Grant (016B80) from the Department of Health and Human Services, Washington, DC.
Antibiotics used appropriately or inappropriately can produce iatrogenic disease. Concern over inappropriate use [2-8] has led to the development of programs aimed at changing physician's antibiotic prescribing habits [2-4]. Such programs do not, however, ease problems of restricted access to necessary antibiotic therapy owing to financial barriers such as inadequate insurance coverage. Providing free medical care to all persons increases access to care. This could improve the quality of antibiotic use, but it could just as likely increase both inappropriate antibiotic use and harmful side effects.

To understand how antibiotics are used, we analyzed data from insurance claims collected as part of the Rand Health Insurance Experiment. We describe how the use of antibiotics in a general non-elderly population varies by gen- 
erosity of insurance, patient demographics, geographic area of the United States, health status, and diagnosis.

\section{METHODS}

\section{The Rand Health Insurance Experiment}

Data for this paper come from the Health Insurance Experiment (HIE). The HIE was a unique social experiment designed to provide better information than heretofore available on the effects of alternative health insurance arrangements. Families participated in the experiment from November 1974 to January 1982. Details of the experimental design, other than those described here, can be found elsewhere $[9,10]$.

Briefly, 5814 individuals from 2005 families were enrolled in the fee-for-service part of the experiment; $70 \%$ participated for 3 years, the remainder for 5. Families lived in one of six sites: Dayton, OH; Seattle, WA; Fitchburg or Franklin County, MA; and Charleston or Georgetown County, SC.

Families with very high incomes were excluded from the experiment. About $3 \%$ of the families contacted were excluded from the experiment because their annual income exceeded $\$ 58,000$ (in 1984 dollars). Also excluded were families in which the head of household was eligible for Medicare or who would become so before the end of the study. Additionally, families participating in the Supplemental Security Income (SSI) program, those eligible for the military medical system, and institutionalized individuals (e.g. in prison or in mental institutions) were excluded. Except for these intentional differences, families were representative of the general population of the area where they resided [9].

Families electing to enroll in the experiment were assigned to one of 14 fee-for-service insurance plans by a random-sampling method that made the distribution of family characteristics as similar as possible in each plan [10]. For the analyses presented here, each plan was assigned to one of two categories. First, in the freecare plan, families received all medical services free of charge $(0 \%$ coinsurance). The second category comprised all the cost-sharing plans, in which families paid 25,50 , or $95 \%$ of their medical bills out-of-pocket up to a stipulated maximum each year that was tied directly to family income. All plans covered with the same assigned coinsurance rate all ambulatory and hospital care, most dental services, mental health services, visual and auditory services, prescription drugs and supplies.

\section{Sources of antibiotic data}

To be reimbursed for oral prescription drugs, participants submitted insurance claim forms that were usually completed by a pharmacist. Injected drugs were usually billed as part of a claim for physician services. Our analysis is based on claims submitted by 5765 individuals who participated for the entire second year of the experiment. We included all claims for antibiotics provided in an ambulatory setting (i.e. not a hospital or nursing home) and grouped them into the following classes: amoxicillin/ ampicillin; all other penicillins; tetracyclines; erythromycin; sulfonamides; cephalosporins; lincomycin and clindamycin; polymyxins; chloramphenicol; aminoglycosides; and nitrofurans. The quantity of pills prescribed per prescription and dosage levels used did not vary by plan, so we did not adjust for these factors in our analyses.

\section{Assigning diagnoses to antibiotics}

We linked each antibiotic to a specific diagnosis. Most often, the prescribing physician made the diagnosis link and recorded it on the insurance form. In a few cases multiple diagnoses were recorded and not linked to drug therapy. After reviewing a complete patient profile, a physician at Rand (GAG), who was blinded to the insurance coverage of the patient, assigned the diagnosis that probably triggered the antibiotic therapy. When an antibiotic could be linked to two diagnoses ( $2 \%$ of the total), the first diagnosis listed by the physician was counted. A diagnosis could be determined for 3793 of 3903 antibiotic claims (97\%).

After linking each antibiotic to a diagnosis, we coded diagnoses into 150 homogeneous groups (an expanded version of an earlier listing of 92 "diagnosis clusters" [11]). Finally, we specified four diagnostic categories for which antibiotics might be appropriately or inappropriately prescribed (Table 1), according to whether an illness was likely to be bacterial (e.g. streptococcal sore throat) or viral (e.g. influenza) or to be one for which antibiotics are standard therapy (e.g. acne).

Estimating use of antibiotics by patient characteristics and insurance plan

We examined differences between groups (such as adults and children or persons who 
Table 1. Diagnostic categories used for antibiotic analyses

I. Usually viral conditions

Acute upper respiratory infection

Influenza

Cough (as a primary diagnosis)

Throat pain, tonsillar hypertrophy (as primary diagnoses)

Viral rashes or exanthems

Chronic rhinitis/hay fever*

II. Viral/bacterial conditions

Acute pharyngitis and tonsillitis

Acute laryngitis and tracheitis

Acute bronchitis

III. Usually bacterial conditions ${ }^{\dagger}$

A. Respiratory infections and conditions

Otitis media

Sinusitis

Streptococcal sore throat

Pneumonia

Emphysema, chronic bronchitis, chronic obstructive pulmonary disease

Asthma

B. Non-respiratory infections and conditions

Sexually transmitted diseases and pelvic inflammatory disease

Conjunctivitis and keratitis

Urinary tract and prostate infections

Vaginitis and cervicitis

Acne

Other skin infections or inflammation (all types)

Lacerations, contusions, and other injuries

IV. All other conditions:

*Hay fever is included here because using antibiotics to treat hay fever is analogous to using antibiotics to treat viral conditions.

+ Not all of these conditions are bacterial in the strict medical sense, but they are included in this category because antibiotic or other antimicrobial usage is accepted, standard therapy when an infection is considered present.

$\ddagger$ All other diagnoses and problems for which care was obtained in the second year of the experiment.

were in good or poor health) with multi-level contingency tables and simple descriptive statistics. We then determined the rate of antibiotic use for each level of the variable of interest and calculated ratios of those rates (e.g. the ratio of the rate of antibiotic use among women to that among men). A Taylor's series $95 \%$ confidence interval was calculated for each ratio [12]. If the confidence interval does not include 1.0, the difference between the two groups is statistically significant at the 0.05 level (two-tailed test).

To explain antibiotic use while controlling for the effects of several variables simultaneously, we used multiple regression techniques. The number of prescriptions purchased during the second year of the experiment was the dependent variable. Explanatory variables were insurance plan, HIE site, income adjusted for site cost-of-living differences and family size and composition, age, age squared, sex, and a person-specific score on a general health ratings index. The health ratings index, an indicator of underlying health status, was computed from 22 questionnaire items ( 7 for children 13 and younger) administered to all participants at the beginning of the second participation year $[13,14]$. The distribution of antibiotics purchased was skewed and non-normal, with most people using none or only one antibiotic per year and a few individuals using as many as 20; to account for this, we fit a negative binomial model to the data [15].

\section{RESULTS}

We present univariate and multivariate analyses on how antibiotic use differs with patient's personal characteristics, demographics, insurance coverage, and diagnosis.

\section{Types of Antibiotics used by Children and Adults}

Among children $(<14 \mathrm{yr}$ of age) the most commonly used oral antibiolics were amoxicillin/ampicillin $(35 \%)$, penicillins $(30 \%)$, and erythromycin (17\%) (Table 2). Two percent of the antibiotics prescribed for children were tetracyclines (about three-quarters of which were for children 9 or older). Among adults, tetracyclines $(25 \%)$ were the most commonly used antibiotic, followed by relatively equal use of penicillins, amoxicillin/ampicillin, and erythromycin.

Injectable antibiotics accounted for $10 \%$ of total antibiotic use. The most commonly injected agents were the penicillins (children, $82 \%$ of all injectable antibiotics; adults, $48 \%$ ). Among children, the second-ranking injectable antibiotics were amoxicillin/ampicillin $(8 \%)$ followed by lincomycin or clindamycin $(4 \%)$. Among adults, the next two commonly injected antibiotics were lincomycin or clindamycin $(28 \%)$ and tetracyclines $(17 \%)$.

\section{Relationship of Antibiotic Use to Demographic and Plan Variables}

\section{Age and sex}

Taking all insurance plans together, children $6 \mathrm{yr}$ and younger used oral antibiotics most frequently: more than 1 antibiotic per child per year (Table 3). After age 6, boys and men used between 0.33 and 0.42 antibiotics per year. Among girls and women, antibiotic use dropped by about one-half for adolescent and teenaged girls, but then rose to 0.72 antibiotics per women per year after age 20 . Overall, women were 1.46 times (confidence interval $(\mathrm{CI})$ : 1.40 , 
Table 2. Number and percentage of oral antibiotics purchased for children and adults, by antibiotic class

\begin{tabular}{|c|c|c|c|c|}
\hline \multirow[b]{2}{*}{ Antibiotic class } & \multicolumn{2}{|c|}{$\begin{array}{c}\text { Children }(<14 \text { yr }) \\
N=1775\end{array}$} & \multicolumn{2}{|c|}{$\begin{array}{c}\text { Adults }(\geqslant 14 \mathrm{yr}) \\
N=3907\end{array}$} \\
\hline & $\begin{array}{l}\text { Number of } \\
\text { antibiotics }\end{array}$ & $\begin{array}{l}\text { Percent of } \\
\text { antibiotics* }\end{array}$ & $\begin{array}{l}\text { Number of } \\
\text { antibiotics }\end{array}$ & $\begin{array}{l}\text { Percent of } \\
\text { antibiotics* }\end{array}$ \\
\hline Penicillins & 414 & 30 & 311 & 15 \\
\hline Amoxicillin/ampicillin & 471 & 35 & 278 & 13 \\
\hline Erythromycin & 237 & 17 & 309 & 15 \\
\hline Tetracyclines & 30 & 2 & 536 & 25 \\
\hline Cephalosporins & 47 & 3 & 124 & 6 \\
\hline Lincomycin/clindamycin & 2 & $<1$ & 23 & 1 \\
\hline Sulfonamides & 49 & 4 & 69 & 3 \\
\hline Nitrofurans & $2 \mathrm{I}$ & 2 & 69 & 3 \\
\hline Aminoglycosides & 4 & $<1$ & 11 & 1 \\
\hline Antifungals & 22 & 2 & 246 & 12 \\
\hline Combinations & 55 & 4 & 99 & 5 \\
\hline Other & 12 & 1 & 38 & 2 \\
\hline Total & 1364 & 101 & 2113 & 101 \\
\hline
\end{tabular}

*Percentages may not sum to 100 because of rounding. Age was unknown for 83 people.

1.53) as likely to use an oral antibiotic as were men.

Injected antibiotics per person per year averaged 0.07. Injections were most common among children 6 and younger $(0.09)$ and among adults 40 and older $(0.12)$. As with oral antibiotics, injections were more common among women than men $(0.08$ and 0.06 per person per year; female:male ratio, 1.31 ; CI: $1.08,1.58$ ).

\section{Health status}

Even though most antibiotics are used for acute conditions, we expected them to be used mainly by individuals in poorer health. To test this hypothesis, we calculated rates of use for persons who were considered to be in "ill health" at the beginning of the second study year according to values on a self- or parentassessed general health ratings index.

All persons whose score on this index was below the median for their age and sex group used more antibiotics annually than those with better-than-average health status. Oral antibiotics were 1.47 times as likely to be used (CI:
$1.41,1.54)$ if people perceived their health to be poorer than average ( 0.72 vs 0.49$)$; injectable antibiotics were 1.35 times (CI: $1.12,1.63)$ as likely to be used ( 0.08 vs 0.06$)$.

\section{Insurance plan}

Age and plan. Children with free care used $73 \%$ more antibiotics (CI: 68, 78) than those on the cost-sharing plans, and adults on the free plan $86 \%$ more (CI: 78, 94). Altogether, participants on the free care plan used $80 \%$ more antibiotics than did people on the cost-sharing plans (CI: 75, 86).

Site and plan. Annual per capita antibiotic use varied by geographic area. Oral antibiotic use was highest in Dayton (0.87 antibiotics per person per year) and lowest in Massachusetts $(0.43)$; Seattle (0.62) and South Carolina (0.59) fell between the two. Dayton physicians also gave injectable antibiotics more frequently than physicians in any other site: 0.24 injections per person per year compared with 0.01 in Massachusetts and 0.04 in both Seattle and South Carolina.

Table 3. Use of oral antibiotics per person per year by age and sex

\begin{tabular}{lccccccc}
\hline & \multicolumn{3}{c}{ Women } & \multicolumn{3}{c}{ Men } \\
\cline { 2 - 3 } $\begin{array}{c}\text { Age group } \\
(\mathrm{yr})\end{array}$ & Number & $\begin{array}{c}\text { Number of } \\
\text { antibiotics }\end{array}$ & $\begin{array}{c}\text { Number } \\
\text { per person }\end{array}$ & Number & $\begin{array}{c}\text { Number of } \\
\text { antibiotics }\end{array}$ & $\begin{array}{c}\text { Number } \\
\text { per person }\end{array}$ \\
\hline $0-6$ & 390 & 470 & 1.21 & & 438 & 519 & 1.18 \\
$7-13$ & 465 & 217 & 0.47 & & 482 & 158 & 0.33 \\
$14-19$ & 360 & 204 & 0.57 & & 380 & 158 & 0.42 \\
$20-29$ & 563 & 428 & 0.76 & & 447 & 166 & 0.37 \\
$30-39$ & 515 & 335 & 0.65 & & 459 & 142 & 0.31 \\
$40-49$ & 283 & 191 & 0.67 & & 261 & 100 & 0.38 \\
50 and over & 365 & 282 & 0.77 & & 274 & 107 & 0.39 \\
Total* & 2992 & 2138 & 0.71 & 2773 & 1357 & 0.49 \\
\hline
\end{tabular}

*Age was unknown for 51 women and 32 men (11 claims for women and 7 for men). 
Table 4. Use of oral, injected, and all antibiotics per person per year by level of family income and insurance plan

\begin{tabular}{|c|c|c|c|c|c|}
\hline \multirow[b]{2}{*}{$\begin{array}{l}\text { Antibiotic use and } \\
\text { income tertile* }\end{array}$} & \multicolumn{2}{|c|}{$\begin{array}{l}\text { Free plan } \\
(N=1935)\end{array}$} & \multicolumn{2}{|c|}{$\begin{array}{c}\text { Cost-sharing plans } \\
(N=3830)\end{array}$} & \multirow{2}{*}{$\begin{array}{c}\text { Ratio of free } \\
\text { to cost-sharing } \\
(95 \% \text { confidence } \\
\text { interval) } \dagger\end{array}$} \\
\hline & $\begin{array}{c}\text { Number of } \\
\text { antibiotics }\end{array}$ & $\begin{array}{l}\text { Number per } \\
\text { person }\end{array}$ & $\begin{array}{l}\text { Number of } \\
\text { antibiotics }\end{array}$ & $\begin{array}{l}\text { Number per } \\
\text { person }\end{array}$ & \\
\hline \multicolumn{6}{|l|}{ Oral antibiotics } \\
\hline Upper one-third & 548 & 0.94 & 723 & 0.58 & $1.63(1.55,1.72)$ \\
\hline Middle one-third & 577 & 0.93 & 669 & 0.57 & $1.62(1.53,1.71)$ \\
\hline Lower one-third & 442 & 0.72 & 386 & 0.33 & $2.17(1.97,2.39)$ \\
\hline All incomes & 1670 & 0.85 & 1825 & 0.48 & $1.79(1.72,1.86)$ \\
\hline \multicolumn{6}{|l|}{ Injected antibiotics } \\
\hline Upper one-third & 45 & 0.08 & 89 & 0.07 & $1.09(0.77,1.54)$ \\
\hline Middle one-third & 69 & 0.11 & 75 & 0.06 & $1.73(1.27,2.36)$ \\
\hline Lower one-third & 38 & 0.06 & 45 & 0.04 & $1.60(1.05,2.44)$ \\
\hline All incomes & 187 & 0.10 & 221 & 0.06 & $1.67(1.39,2.01)$ \\
\hline \multicolumn{6}{|l|}{ All antibiotics } \\
\hline Upper one-third & 593 & 1.02 & 812 & 0.65 & $1.57(1.51,1.63)$ \\
\hline Middle one-third & 646 & 1.04 & 744 & 0.64 & $1.63(1.57,1.70)$ \\
\hline Lower one-third & 480 & 0.78 & 431 & 0.37 & $2.11(1.94,2.30)$ \\
\hline All incomes & 1857 & 0.96 & 2046 & 0.53 & $1.80(1.75,1.86)$ \\
\hline
\end{tabular}

* Numbers shown for income tertiles do not sum to totals because income was unknown for 138 claims on the free plan and 59 on the cost-sharing plans.

$\dagger$ Taylor's series $95 \%$ confidence intervals [12]; ratio and confidence intervals calculated using 8 significant digits.

For all geographic areas, use of oral antibiotics was higher with free care. Plan differences were greatest in South Carolina: persons on the free plan used $134 \%$ more antibiotics (CI: 119, 151). Differences were smallest in Seattle: $30 \%$ more (CI: 19, 42).

Family income and plan. Regardless of plan, people in the lowest third of the income distribution (adjusted for geographic area) used the fewest antibiotics (Table 4). Having free care significantly diminished the effect of income on use of antibiotics. With free care, persons in the highest income group used about one-third more antibiotics than did those in the lowest income group; on the cost-sharing plans, use among persons with the highest incomes was about three-quarters again as great.

For oral antibiotics the largest free-to-costsharing ratio occurred among persons in the lowest income group (Table 4); their ratio of 2.17 was significantly different from those of persons in the middle or upper thirds of the income distribution. People in the lowest income tertile had the fewest injections regardless of insurance plan; poor people on the free plan used $60 \%$ more injected antibiotics than those on the cost-sharing plans.

Effects of insurance plan, income, age, sex, site, ill health on use of oral antibiotics

Antibiotic use was associated with several demographic and experimental variables when examined one at a time. To understand the collective and separate effects of these variables, we used a negative binomial regression model to estimate the rate of oral antibiotic use [16]. Cost sharing, older age, being male, having lower income, and being in better health were all significantly associated with using fewer oral antibiotics per person per year. The ratios produced by the model are very close to those found in the univariate and bivariate analyses. For example, even when no other variables are controlled for, individuals on the free plan used $80 \%$ more antibiotics than those on the costsharing plans; when age, sex, income, health status, and geographic area are held constant, we estimate $85 \%$ more antibiotic use on the free plan. These similarities are not surprising because demographic characteristics were balanced across plans at the beginning of the experiment.

Table 5 presents several examples of annual rates of oral antibiotic use predicted by our multivariate model, holding geographic site and health status constant. For example, we estimate that high-income girls on the free plan used 2.48 antibiotics per year (the highest rate among the various groups examined); at 0.09 per year, low-income men on the cost-sharing plan used the fewest antibiotics.

We can use these examples to address more concretely two important questions: "Given that a person is poor, how much more will that 
Table 5. Annual per-person rate* of oral antibiotic use for persons of different family income, sex, and ages by insurance plan

\begin{tabular}{llllll}
\hline & \multicolumn{2}{c}{ Free plan } & & \multicolumn{2}{c}{ Cost-sharing plans } \\
\cline { 2 - 3 } \cline { 5 - 6 } Sex and age & $\begin{array}{c}\text { Low } \\
\text { income }\end{array}$ & $\begin{array}{c}\text { High } \\
\text { income }\end{array}$ & & $\begin{array}{c}\text { Low } \\
\text { income }\end{array}$ & $\begin{array}{c}\text { High } \\
\text { income }\end{array}$ \\
\hline $\begin{array}{l}\text { Female } \\
4 \text { yr }\end{array}$ & 1.82 & 2.48 & & 1.06 & 1.14 \\
$\begin{array}{c}45 \mathrm{yr} \\
\text { Male }\end{array}$ & 0.49 & 0.67 & & 0.14 & 0.53 \\
$4 \mathrm{yr}$ & 1.15 & 1.57 & & 0.67 & 0.72 \\
$45 \mathrm{yr}$ & 0.31 & 0.42 & & 0.09 & 0.33 \\
\hline
\end{tabular}

*Per-person rates are predicted using a negative binomial model [16] holding health status and geographic site constant.

person use antibiotics if he or she has free medical care rather than shares in the cost of care?" and "If people have free care, how much will use of antibiotics differ between those who are poor and those who are well-to-do?" Having free care markedly increases the use of antibiotics: compared with individuals in the costsharing plans, poor women with free care use about $250 \%$ more antibiotics ([0.49-0.14]/ $0.14=2.50$ ); poor men use about $244 \%$ more; and poor children about $72 \%$ more. Even with free care, however, use would continue to differ by income level. Poor persons with free care use about $27 \%$ fewer antibiotics than well-off persons (e.g. $[2.48-1.82] / 2.48=0.27$ for 4-year-old girls).

\section{Antibiotic use by diagnosis}

One way to determine if different levels of cost sharing (including none) are associated with over- or under-use of antibiotics is to see if the proportions of antibiotics given for various diagnostic categories differ. We calculated the percentage distribution of all antibiotics across four broad diagnostic categories-viral, viral-bacterial, bacterial, and other; these distributions did not differ appreciably by plan (Table 6). Viral conditions such as upper respiratory infections, for which the indications for antibiotic use are equivocal at best, accounted for 17 and $16 \%$ of antibiotics purchased on the free and cost-sharing plans, respectively. The percentages of antibiotics that were used for the viral-bacterial, bacterial, and other categories were also nearly identical for the two plans.

Individuals with free care used more antibiotics per person than those on the cost-sharing plans for all four diagnostic categories. The differential extended from $56 \%$ more for viral-bacterial conditions to $97 \%$ more for viral conditions. Yet, other results from the Health Insurance Experiment show no significant differences in health status for the average participant by insurance plan $[17,18]$.

\section{DISCUSSION}

We have shown that insurance coverage, sex, age, gengraphic area, health status, and income influenced antibiotic use. People with more generous insurance use $85 \%$ more antibiotics per person per year than people who shared in the costs of their medical care, even controlling for the influence of demographic and personal characteristics. Being female, being young, being in "ill health" (below the median of a parent- or self-assessed health ratings index), and being of higher income led to significantly higher rates of antibiotic use.

Other work in the Health Insurance Experiment has shown that annual drug expenditures in an ambulatory setting rise as the level of cost sharing falls [19]. Drug expenditures per person on the free care plan were about $60 \%$ higher than on our least generous plans (95\% coinsurance). This increase in total drug expenditures is about the same as that observed for total per capita outpatient expenditures and suggests that drug use increased at the same rate as did physician visits. The number of total prescriptions purchased per person was significantly higher on the free plan and varied across plans in the same fashion as did drug expenditures. Finally, no difference was found by plan for average charge per prescription so plan differences are related to the quantity of drugs purchased. Thus, the effect of cost sharing on antibiotic use comes principally through a reduction in visits rather than as a result of reduced antibiotic prescribing given a visit.

The types of antibiotics purchased were similar for participants on the free and cost-sharing plans. Moreover, the pattern was consistent with that reported by the National Ambulatory Medical Care Survey [1], so our experimental population's aggregate use of antibiotics reflects what might be expected for the nation as a whole.

Antibiotic use varied widely, however, across our four regions: highest in the Central region site, lowest in the Northeast sites. These variations were not explained by income or other population differences. The symptoms or conditions for which our participants sought care (apart from the higher use associated with free 


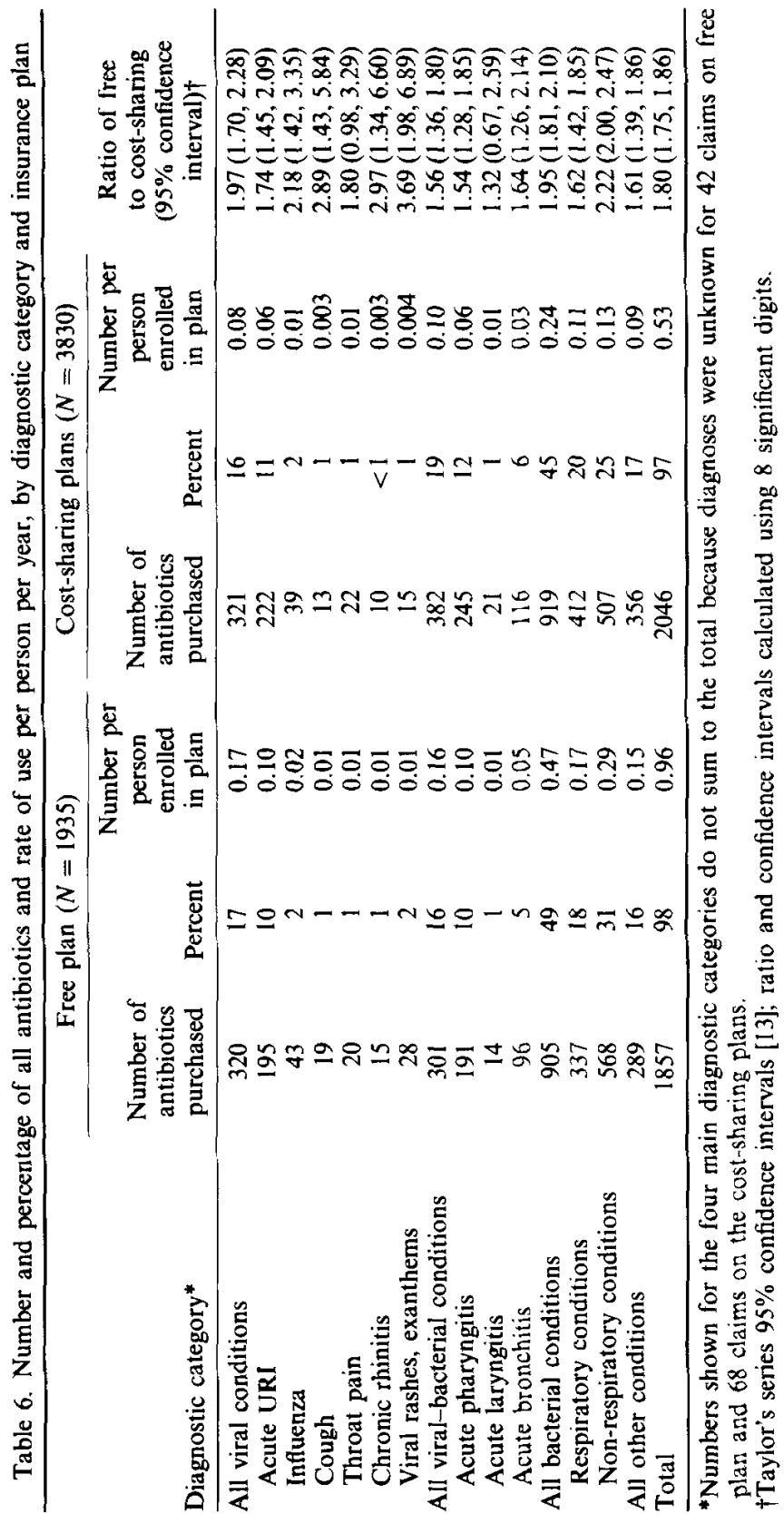


care per se) and variations in the type of physician and his or her training may explain part or all of the site differences in antibiotic use; this question is currently under investigation.

Was free care likely to increase antibiotic use nonspecificially or only for appropriate diagnoses? At the beginning of the experiment, families were randomly assigned to insurance plans, and we observed no differences by plan in the prevalence of over two dozen chronic conditions such as acne or several acute illnesses such as otitis media [20, 21]. Hence, we would not expect the incidence of ailments for which antibiotic treatment would be the norm to differ by plan. We observed, however, that antibiotic use was greater on the free than on the cost-sharing plans across all diagnoses, even those where antibiotic use is not beneficial (i.e. viral conditions). Thus, free care evidently had a general, nonspecific effect on increasing antibiotic use.

Although antibiotics have unquestionable benefits, they also have adverse effects. We estimate using published rates [22] of adverse reactions associated with each antibiotic class that 5 serious adverse effects from antibiotics would have occurred per 1000 persons enrolled on the cost-sharing plans as compared with 10 per 1000 on the free plan. For mild plus serious adverse effects the figures are 44 and 65 per 1000 on the cost-sharing and free plans, respectively. Based on the physician's reason for using an antibiotic, $18 \%$ of the possible serious adverse drug reactions (across all plans) would be associated with antibiotics given for viral conditions. Thus, cost-sharing reduced an individual's probability of suffering an adverse effect because the overall rate of antibiotic use was lower on cost-sharing plans. It did not, however, decrease the probability that an adverse reaction (if experienced) was caused by inappropriate use of the drug.

As a possible strategy for dealing with inappropriate antibiotic use, cost sharing falls short on two counts. On average, cost sharing lowered antibiotic use by $46 \%$; although a considerable amount of inappropriate prescribing remained, the rate of appropriate use was also reduced to a similar degree. Thus, a more selective method, one that curtails inappropriate use while maintaining access to needed and appropriate antibiotics, is required.

Clinically based programs, which teach physicians appropriate principles of antibiotic therapy, constitute one approach that should be tested more fully. Some programs of this sort have had limited success [23-25]. Efforts to develop them further, with the aim of creating the desirable economic incentives of cost sharing without the attendant negative effects on access to needed care, should be strongly encouraged.

Acknowledgements - This research was supported by the Health Insurance Study Grant 016B80 from the Department of IIealth and IIuman Services, Washington, DC, We are indebted to many individuals who over the years have given dedicated support to the overall project. We would like to acknowledge in particular the substantive contributions of our Rand colleagues William R. Rogers and Caren $\mathbf{J}$. Kamberg and the secretarial assistance of Barbara Eubank.

\section{REFERENCES}

1. National Center for I Iealth Statistics. Drug Utilization in Office-based Practice. Vital and Health Statistics, Series 13, No. 65. Hyattsville, MD: Department of Health and Human Services, 1982 (DHHS publication no. (PHS) 83-1726)

2. Schaffner W, Ray WA, Federspiel CF: Surveillance of antibiotic prescribing in office practice. Ann Intern Med 89: 796-799, 1978

3. Lohr KN, Brook RH, Kaufman MA: Quality of care in the New Mexico Medicaid Program (1971-1975). Med Care 18(Suppl. 1): 1-129, 1980

4. Bernstein LR, Barriere SL, Conte JE: Utilization of antibiotics: Analysis of appropriateness of use. Ann Emerg Med 11: 400-403, 1981

5. Buckwold F, Ronald AR: Antimicrobial misuse-effects and suggestions for control. J Antimicrob Chemother 5: 129-136, 1979

6. Stamps P, Kirk J, Catino D et al:: Use of antibiotics in primary care. QRB 8: 16-21, 1982

7. Levy B: Microbial resistance to antibiotics: An evolving and persistent problem. Lancet 2(8289): 83-88, 1982

8. McSherry JA: Why not prescribe antibiotics for "heavy colds"? J R Coll Gen Pract 31(222): 49, 1981

9. Newhouse JP, Manning WG, Morris CN et al:: Some interim results from a controlled trial of cost sharing in health insurance. N Engl J Med 305: 1501-1507, 1981

10. Morris C: A finite selection model for experimental design of the Health Insurance Study. J Econometrics 11: 43-61, 1979

11. Schneeweiss R, Rosenblatt RA, Cherkin CD et al:: Diagnosis clusters: A new tool for analyzing the content of ambulatory medical care. Med Care 21(1): $105-122,1983$

12. Kleinbaum DG, Kupper LL, Morgenstern H: Epidemiologic Research: Principle and Quantitative Methods. Belmont, CA: Lifetime Learning Publications, 1982, pp. 296-299

13. Manning WG, Newhouse JP, Ware JE Jr: The status of health in demand estimation. Beyond excellent, good, fair, and poor. In Economic Aspects of Health. Fuch VR (Ed.). Chicago, IL: University of Chicago Press, 1981

14. Davies AR, Ware JE Jr: Measuring Health Perceptions in the Health Insurance Experiment. Santa Monica, CA: The Rand Corporation, 1981 (Rand publication no. R-271 I-HHS)

15. Hausman J, Hall BH, Griliches Z: Econometric models for count data with an application to the patents-R\&D relationship. Feonometrica 52: 909-938, 1984 
16. Foxman B, Valdez RB, Lohr KN, Brook RH, Newhouse JP: The Effect of Coinsurance on the Use of Antibiotics. Results from the Rand Health Insurance Experiment. Santa Monica, CA: The Rand Corporation, forthcoming (Rand publication no. R-3317HHS)

17. Brook RH, Ware JE Jr, Rogers WH et al:: Does free care improve adults' health? Results from a randomized controlled trial. N Engl J Med 309: 1426-1434, 1983

18. Valdez RB, Brook RH, Rogers WH et al:: Consequences of cost-sharing for children's health. Pediatrics 75: 952-961, 1985

19. Leibowitz A, Manning WG, Newhouse JP: The Demand for Prescription Drugs as a Function of Cost Sharing. Santa Monica, CA: The Rand Corporation, 1985 (Rand publication no. N-2278-HHS)

20. Brook RH, Lohr KN, Goldberg GA et al:: Conceptualization and Measurement of Physiologic Health for Adults. Santa Monica, CA: The Rand Corporation, 1980-1983, Vols 2-17 (Rand publication no. R-2262HHS)

21. Lohr KN, Kamberg CJ, Brook RH et al:: Measurement of Physiologic Health for Children. Santa Monica CA: The Rand Corporation, 1983 1985, Vols $1-5$ (Rand publication no. R-2898-HHS)

22. Hemminki E: Adverse reactions to antibiotic drugs: The present scope of the problem in outpatient care and possibilities for improvement. Int $\mathbf{J}$ Hlth Serv 11: 283-301, 1981

23. Schaffner W, Ray WA, Federspiel CF, Miller WO Improving antibiotic prescribing in office practice: a controlled trial of three educational methods. JAMA 250: 1728-1732, 1983

24. Ray WA, Schaffner W, Federspiel CF: Persistence of improvement in antibiotic prescribing in office practice. JAMA 253: 1774-1776, 1985

25. Avorn J, Soumerai SB: Improving drug-therapy decisions through educational outreach. $\mathbf{N}$ Engl J Med 308: $1457-1463,1983$

\section{APPENDIX}

Negative Binomial Regression Model

The negative binomial function offers an attractive basis for modeling the use of antibiotics by participants in the Health Insurance Experiment [15]. It allows us to explain the number of new prescriptions added by the $i$ th individual in one year, $n_{i}$ as follows:

where

$$
P\left(N=n_{i}\right)=\frac{\lambda_{i}^{i} \exp \left(-\lambda_{i}\right)}{n_{i} !}
$$

$$
\begin{gathered}
\lambda_{i}=A_{i} \exp \left(x_{i} \delta\right) \\
A_{i} \approx \Gamma(\theta)
\end{gathered}
$$

for

$\lambda_{i}=$ rate at which prescriptions are accumulated by $i$ th person

$N=$ random variable

$\Gamma(\theta)=$ gamma distribution with parameters, $\theta$ and $\psi$, where $\psi$ is held constant.

This model uses information on level of use $\left(n_{i}\right)$ and characteristics of the individual $\left(x_{i}\right)$ to estimate $\delta$ and $\theta$,
Table A1. Negative binomial model predicting oral antibiotic use

\begin{tabular}{lcr}
\hline Variable & Coefficient & \multicolumn{1}{c}{$t$-test } \\
\hline Intercept & 2.376 & 3.47 \\
Cost-sharing & -0.676 & -7.92 \\
Income adjusted for family size & 0.187 & 2.56 \\
Age & -0.074 & -9.62 \\
Age squared & 0.0009 & 6.66 \\
Male & -0.458 & -6.50 \\
Dayton & 0.192 & 1.69 \\
Fitchburg & -0.367 & -2.65 \\
Franklin County & -0.478 & -3.09 \\
Charleston County & -0.233 & -1.42 \\
Georgetown County & 0.099 & 0.70 \\
Health status & -0.024 & -10.46 \\
Income $\times$ cost-sharing & 0.433 & 3.24 \\
Age $\times$ income $\times$ cost-sharing & 0.012 & 3.67 \\
Age-squared $\times$ income $\times$ & & \\
cost-sharing & -0.0005 & -2.40 \\
Log alpha & -1.201 & -19.36 \\
\hline Number of
\end{tabular}

Number of observations $=5043 ; \log$ likelihood $=4859.4$.

which permit us to explain how elements of $x_{i}$ affect the level of $n_{i}$.

If $A_{1}$ were not distributed as a gamma distribution with parameter $\theta$, but instead was constant and equal for all $i$, equations (2) and (3) together would define a Poisson model. We would have to make two important assumptions to use this simplified version of the model. First, additions are assumed independent of each other. Because our data do not indicate clustering, this assumption is not a bad approximation. Second, the mean and variance of the distribution of prescriptions should be equal to $\lambda$ for the Poisson to be a good approximation. This assumption is too restrictive. Instead of assuming all $A_{t}$ are equal to a common constant, we assume they are distributed according to a gamma distribution, turning our model back into a negative binomial model.

The negative binomial model works in the following way. A gamma distribution can represent a wide range of functions, depending on the value of $\theta$, which is to be estimated. We can interpret $A_{i}$ as follows: For every person, we have a set of observable characteristics, $x_{i}$, which affect antibiotic use. In addition for every person, there are characteristics we did not observe, and these factors also influence use. Therefore, we may have two persons with identical values of independent variables but with different levels of antibiotic use. Different realizations, $A_{i}$ and $A_{i}$, from the gamma distributions, $\Gamma(\theta)$, may be assumed to be the reason for this unexplained difference in use levels of these observations.

In drawing inferences, we cannot make different predictions for these two observations, but our inferences will indicate the general tendency of the use rate, given a set of values for the independent variables. Individuals will have different realizations of use rates around this general tendency according to a gamma distribution. In sum, this model incorporates our ignorance about decisions to use antibiotics by individuals but allows us to make inferences about the general tendency to use antibiotics.

Table Al gives pertinent information about the final model used to generate the predictions shown in Table 5 of the main text. 